\section{Teología de la historia como teología de la acción*}

\author{
Edgar Antonio López ${ }^{* *}$
}

RECIBIDO: 06-05-15 - APROBADO: 06-07-15

Resumen: Se propone comprender la teología de la historia a partir de la teología de la acción. La aplicación del método de interpretación textual a la acción humana permite establecer un paralelo entre la acción orientada significativamente y la interpretación de textos desde tres criterios: la fijación del significado en el tiempo, la autonomía semántica y la intencionalidad trascendente que se abre universalmente a insospechadas interpretaciones. Estos permiten aproximarse teológicamente a la acción humana atendiendo los resultados históricos en los que ella se revela como acción liberadora de Dios.

Palabras clave: Historia, acción humana, teología de la historia, teología de la acción, interpretación.

PARA CITAR ESTE ARTÍCULO:

López, Edgar Antonio. "Teología de la historia como teología de la acción” Theologica Xaveriana 180 (2015): 471-496. http://dx.doi.org/10.11144/javeriana.tx65-180.thta
Theology of History as Theology of Action

Aвstract: This article intends to understand Theology of history from the perspective of Theology of action. Applying the method of textual interpretation to human action allows to establish a parallel between meaningfully oriented action and the interpretation of texts based on three criteria: meaning fixed in time, semantic autonomy, and transcendent intentionality opened universally to interpretations. These criteria enable a theological approach to human action according to its historical effects, which reveal it as God's liberating action.

KeY words: History, Human action, Theology of history, Theology of action, Interpretation. Teologia da história como teologia
da ação

Resumo: Propóe-se compreender a teologia da história partindo da teologia da ação. A aplicação do método de interpretação textual à ação humana permite estabelecer um paralelo entre a ação orientada significativamente e a interpretação de textos partindo de três critérios: a fixação do significado no tempo, a autonomia semântica e a intencionalidade transcendente que se abre universalmente insuspeitas interpretaçóes. Estes permitem aproximar-se teologicamente à ação humana atendendo aos resultados históricos nos que ela se revela como ação libertadora de Deus.

Palavras chave: História, ação humana, teologia da história, teologia da ação, interpretação.

\footnotetext{
*Artículo de reflexión resultado del Seminario de Profesores Teología de la Acción (2014-2015), Departamento de Teología, Pontificia Universidad Javeriana (Bogotá).

** Doctor y Magíster en Teología, Pontificia Universidad Javeriana (Bogotá). Profesor asociado de la Facultad de Teología, Pontificia Universidad Javeriana. Correo electrónico: lopez@javeriana.edu.co
} 
La reflexión de los hechos históricos a la luz de la fe ha estado presente a través de los milenarios procesos que dieron forma al pueblo de Israel y luego también a las iglesias cristianas. Las comunidades creyentes judías y cristianas han visto en la historia un lugar en el que acontece la revelación de Dios. El resultado de su particular interpretación de la historia ha sido consignado en las Sagradas Escrituras ${ }^{1}$ y ha hecho de ellas, a su vez, un hontanar de criterios para interpretar el sentido de los hechos históricos y para orientar las acciones humanas hacia la construcción de nuevos mundos posibles, más próximos a la realización histórica del Reino de Dios.

Más que un área teológica derivada de alguna especialización funcional de la teología ${ }^{2}$ o de la ontología de la comprensión que fundamenta y explica las especializaciones teológicas ${ }^{3}$, la teología de la acción es propuesta aquí de modo pragmático como una manera de hacer teología que capta la acción continua de Dios en la historia mediante las acciones humanas ${ }^{4}$, las cuales han de ser objeto de percepción, análisis y planificación. ${ }^{5}$

Esta forma de hacer teología se ocupa de la actividad humana a partir de la realidad concreta para transformarla bajo el impulso de la Palabra, que se hace acción posibilitadora del Reino de Dios en la historia. ${ }^{6}$

De acuerdo con la visión que Ignacio Ellacuría tiene de la historia como proceso creacional en el que se da la actualización de posibilidades ${ }^{7}$, la teología de la historia es presentada en este artículo como el esfuerzo por captar la trascendencia de la historia y transformarla mediante la historización del Reino de Dios. ${ }^{8}$ Esto responde a la doble visión del Reino propuesta por el teólogo vasco-salvadoreño como historia trascendente y como trascendencia histórica. ${ }^{9}$

\footnotetext{
(Schillebeeckx, Los hombres relato de Dios, 31).

${ }^{2}$ Lonergan, Method in Theology, 125-126.

${ }^{3}$ Parra, Textos, contextos y pretextos. Teologia fundamental, 56-68.

${ }^{4}$ López, "En el perdón de las víctimas está nuestra esperanza”, 17.

${ }^{5}$ Ibid., 17, 20.

${ }^{6}$ Parra, "De camino a la teología de la acción", 165-166.

${ }^{7}$ Ellacuría, Filosofía de la realidad histórica, 514-563.

${ }^{8}$ Idem., "Utopía y profetismo”, 394-399.

${ }^{9}$ Ibid., 396.
}

1 "Los hechos se vuelven historia tan solo en un marco de sentido, en una tradición de hechos interpretados. Este es el primer nivel de sentido que se lleva a cabo y se experimenta la liberación humana. En una tradición experiencial religiosa de fe en Dios, ese momento humano de liberación es interpretado en un segundo nivel de sentido: en relación con Dios. Los creyentes confiesan entonces que Dios ha traído, en y a través de hombres, redención. El acontecer profano se torna el material de la 'palabra de Dios'." 
En su pretensión de ampliar el estudio del obrar humano más allá de las fronteras de las comunidades creyentes ${ }^{10}$, la teología de la acción debe ocuparse del acontecer de la acción humana en el mundo percibiendo en toda ella el actuar liberador de Dios. $\mathrm{Al}$ reconocer la autonomía de las realidades terrenas ${ }^{11}$, la teología de la acción puede abrir de manera novedosa la posibilidad de comprender y desarrollar la teología de la historia. Tal posibilidad representa a la vez una oportunidad para que la teología de la acción rebase los límites de una pura metafísica de la acción que corre el riesgo de agotarse en un intemporal presente.

En cuanto es ciencia de la comprensión, la teología indaga por el sentido de la historia y de la acción humana. Como entidades semióticas, los fenómenos históricos pueden ser interpretados como objetivaciones de las acciones humanas que permanecen en el tiempo y que, más allá de las intenciones del agente, revelan nuevos mundos por construir a quienes los interpretan desde contextos diferentes y situaciones ulteriores.

Así como un texto es mucho más que un agregado de oraciones y su sentido no puede colegirse del sentido de cada oración, la historia tampoco puede ser comprendida en forma adecuada como una continua sedimentación de acciones individuales o colectivas que la conformarían desde el plano de la corta duración. La interacción entre el presente de la acción y la historia que resulta de ella puede ser la clave para dar con una teología de la acción atenta al sentido histórico del obrar humano y con una teología de la historia que permita actualizar el sentido de este actuar.

Superada ya la visión de una historia de la salvación como acontecer paralelo a la historia profana, la única realidad histórica debe ser aceptada como lugar teológico en

10 “Teólogo de la acción es quien instituye su reflexión teológica a partir del obrar humano en la práctica cultural, económica, política, social, eclesial, doméstica y laboral, ya sea que se trate del hacer, del realizar o del teorizar la práctica humana para dinamizar el proceso integral de transformación presente y trascendente a la luz del proyecto de Dios y de su plan de gracia [...]. Quizás pueda convenirse que la teología de la acción desbloquea los exclusivismos de personas y de sectores que se han visto comprometidas, tanto la teología pastoral como la teología de la liberación." (Parra, "De camino a la teología de la acción”, 160-161; 166).

11 "Si por 'autonomía de las realidades terrenas' entendemos que las cosas y las sociedades tienen sus propias leyes y su propio valor, y que el hombre debe irlas conociendo, empleando y sistematizando paulatinamente, es absolutamente legítima esa exigencia de autonomía, que no solo la reclaman los hombres de nuestro tiempo, sino que responde además a la voluntad del Creador. El cual, por el hecho mismo de la creación, dio a las cosas una propia firmeza, verdad, bondad, propias leyes y orden que el hombre está obligado a respetar, reconociendo el método propio de cada una de las ciencias o artes." (Concilio Vaticano II, “Constitución pastoral Gaudium et spes sobre la Iglesia en el mundo actual” 36). 
que convergen la acción de Dios y la acción humana. ${ }^{12}$ Sin embargo, es evidente que no todas las acciones humanas se orientan a la construcción del Reino de Dios, pues algunas de ellas alienan, infligen dańo o causan violencia y dolor. Ante la presencia del mal en el mundo, es necesario entonces superar el ingenuo providencialismo según el cual "Dios escribe derecho con letras torcidas", como pretendían en el siglo XVII posturas como la del "todo está bien" de Jacobo Benigno Bossuet. ${ }^{13}$

La tarea de percibir el actuar liberador de Dios en la historia ha de ser asumida en forma crítica por la teología de la acción. Esto implica para ella volver la mirada a la pasividad como contraparte de la acción y descubrir entonces la presencia de Dios en las tragedias humanas. En este sentido, decía bien el mártir Ignacio Ellacuría: "Aun en el caso del pecado estamos en plena historia de la salvación: el pecado no hace desaparecer a Dios, sino que lo crucifica." ${ }^{14}$

Actualmente, la teología debe ocuparse de la historia teniendo presente que ella no es una trama unitaria y progresiva de acontecimientos. El concepto mismo de "historia universal", que permitió a pensadores como Emmanuel Kant ${ }^{15}$ y Wilhelm Friedrich Hegel ${ }^{16}$ explicar el curso unívoco de la historia, es difícil de aceptar en la actualidad, a pesar de la seguridad que ofreció a la teología durante mucho tiempo. Así lo expresa el teólogo español Andrés Tornos:

Quizás el mayor desafío con que se enfrenta hoy la teología de la historia es la crisis en la que el saber profano roe la denominación misma de la historia universal [...]. El debate entre modernidad y posmodernidad se introduce con esto en la reflexión religiosa. Y en verdad fuerza a esta a una opción difícil. Porque la concepción del avance unitario de la historia no solo ha sido tan central en los últimos siglos de la cultura europea que su oscurecimiento y crisis se experimentan como un oscurecimiento de las razones últimas de vivir; es que además esa crisis pone en cuestión la unidad de la razón humana

12 "Desde un principio damos por aceptado que no se dan dos historias, una historia de Dios y una historia de los hombres, una historia sagrada y una historia profana. Más bien lo que se da es una sola realidad histórica en la cual interviene Dios y en la cual interviene el hombre, de modo que no se da la intervención de Dios sin que en ella se haga presente de uno u otra forma el hombre y no se da la intervención del hombre sin que en ella se haga presente de algún modo Dios." (Ellacuría, "Historicidad de la salvación cristiana”, 327).

\footnotetext{
${ }^{13}$ Bossuet, Discurso sobre la historia universal.

${ }^{14}$ Ellacuría, "Historicidad de la salvación cristiana", 328.

${ }^{15}$ Kant, "Idea de una historia universal en sentido cosmopolita".

${ }^{16}$ Hegel, Lecciones sobre la filosofía de la historia universal.
} 
en lo ético-práctico primero, pero por ello mismo también la validez de toda pretensión de universalidad. ${ }^{17}$

Tras el fin de los metarrelatos, tan útiles para explicar una historia pretendidamente universal, la teología debe fijar ahora su atención en las historias singulares, prestando suficiente atención a la dialéctica entre procesos de corta y larga duración que dan forma a las comunidades y a los grupos sociales en contextos particulares. Entre las acciones humanas, individuales y colectivas, y sus efectos, que permanecen abiertos a la interpretación a lo largo del tiempo, hay una interacción en la cual los creyentes pueden ver cómo Dios revela su poder liberador.

A continuación será introducida la categoría de duración, como un recurso de la teoría histórica, que puede ser de gran valor para la teología de la historia; luego será asumida la aplicación que hace Ricoeur de la teoría textual a la acción humana, simplificando su propuesta a tres criterios, que corresponden a la fijación del significado en el tiempo, la autonomía semántica y la intencionalidad trascendente que abre la acción a inéditas interpretaciones.

\section{Fugacidad y permanencia}

En su habilitación como Privatdozent en la Universidad de Friburgo, el 27 de julio de $1915^{18}$, Martin Heidegger se preguntaba sobre la estructura del concepto de tiempo propio de la ciencia histórica. En aquella ocasión, el pensador alemán subrayó la diferencia existente entre la continuidad homogenea del tiempo de la física y la discontinuidad cualitativa del tiempo de la historia.

El reconocimiento de la significatividad fundamental que tiene el concepto de tiempo en la historia y de su radical diferencia con respecto al concepto de tiempo en la física permitirá a la teoría de la ciencia penetrar en el peculiar carácter de la ciencia histórica y fundarla teóricamente como un modo de pensar original e irreductible a otras ciencias. ${ }^{19}$

Una adecuada comprensión de la historia como disciplina, de sus maneras de investigar y de su comprensión de la temporalidad, permite a la teología de la historia aproximarse con mayor cuidado a la realidad histórica como lugar de convergencia de la acción divina y la acción humana.

\footnotetext{
${ }^{17}$ Tornos, "Sobre teología de la historia”, 180.

${ }^{18}$ Heidegger, "El concepto del tiempo en la ciencia histórica".

${ }^{19}$ Ibid., 38.
} 
En su clásico ensayo de 1958, “La larga duración”, Fernand Braudel mostraba a sus contemporáneos la importancia que tiene, para las ciencias humanas y las ciencias sociales, atender a "esos tiempos múltiples y contradictorios de la vida de los hombres que no son únicamente la sustancia del pasado, sino también la materia de la vida social actual" ${ }^{20}$

Con ello, este historiador francés hacía referencia a la pluralidad de tiempos sociales cuya relación dialéctica constituye lo que se denomina duración: esa "viva e íntima oposición, infinitamente repetida entre el instante y el tiempo lento en transcurrir" ${ }^{21}$, indispensable para comprender la realidad social.

Tal multiplicidad de tiempos en constante interacción puede servir hoy a la teología para pensar la relación entre la acción humana del tiempo subjetivo y el tiempo social en que esta perdura, a través de sus consecuencias históricas, expuestas a inéditas interpretaciones ulteriores. La relación entre la fugacidad de la acción y la permanencia histórica de sus efectos puede ser la clave para comprender mejor la acción de Dios en la historia por medio del actuar humano. ${ }^{22}$

Durante mucho tiempo, en el proceso de configuración de la historia como disciplina, se pensó en los acontecimientos como único recurso explicativo; "se forjó la ilusión de que todo podía ser deducido de los acontecimientos". ${ }^{23}$ La historia de los anales, escuela a la que perteneció Braudel, se caracteriza por la fuerte crítica a este recurso propio de la tradicional historia de "gestas y héroes", tan similar a algunas visiones cándidas de la historia de la salvación que toman por verdad histórica la innegable autenticidad de las narrativas bíblicas.

Esa visión, "atenta al tiempo breve, al individuo y al acontecimiento"24, se detiene en el carácter fugaz del acontecimiento sin atender a su significado. "El tiempo corto es la más caprichosa, la más engañosa de las duraciones”25, afirmaba el historiador

\footnotetext{
${ }^{20}$ Braudel, "La larga duración", 62-63.

${ }^{21}$ Ibid., 63.

22 "Se afirmará con Gogarten que los hechos, la actividad, el hacer, la acción humana que proceden de la historicidad del ser y constituyen la historia son el medio para la mostración amorosa y libre de Dios en el mundo; que cuando ocurre la divina revelación ocurren los hechos de la actividad humana en el mundo, y cuando ocurren los hechos de la actividad humana en el mundo ocurre la mostración incondicionada de Dios en el mundo, en el tiempo, en la historia." (Parra, "De camino a la teología de la acción”, 158-159).

${ }^{23}$ Braudel, "La larga duración", 84.

${ }^{24}$ Ibid., 64.

${ }^{25}$ Ibid., 66.
} 
francés, para quien la superación de la visión estrecha del tiempo corto representó un gran avance en la historiografía. ${ }^{26}$

Conviene hoy a la teología de la acción tomar nota de este desarrollo historiográfico, para preguntarse más por el sentido del obrar humano en el mundo que por el mundo del actuar en sí mismo como si se tratase de algo intemporal.

La superación de la perspectiva corta implicó, para la ciencia histórica, una mejor comprensión de los procesos históricos, y aun de los acontecimientos, por fijar la atención en periodos cortos caracterizados por cambios vertiginosos, explicables a partir de coyunturas en las que convergen diferentes factores, que alternan con periodos prolongados de estabilidad, en los cuales el cambio es difícil de percibir. ${ }^{27}$

Quizás el sentido de las acciones humanas cotidianas pueda ser mejor comprendido por la teología desde una perspectiva amplia, que permita fijar la atención en las relaciones del actuar humano con procesos coyunturales más complejos y con procesos estructurales de larga duración. ${ }^{28}$

Es así como la teología de la acción puede hacer posible una nueva forma de teología de la historia y valerse de ella, a la vez, para atender a la complejidad que representa la interpretación del obrar humano más allá del tiempo subjetivo, propio de la percepción que tiene una persona de la vida cotidiana.

En lo que sigue se mostrará la importancia que tienen la temporalidad, la alteridad y la trascendencia del actuar en este intento de concebir la teología de la historia como teología de la acción.

\section{Temporalidad y exteriorización}

La fugacidad del instante volátil, en la cotidianidad del tiempo subjetivo, puede compararse con la evanescencia de una conversación. No obstante, mediante su registro, lo dicho durante la conversación perdura en el tiempo con una permanencia que puede abrirse a la mediana y a la larga duración.

${ }^{26}$ Ibid., 67.

${ }^{27}$ Idem, El Mediterráneo y el mundo mediterráneo en la época de Felipe II, 17. Esta distinción entre procesos de corta, mediana y larga duración es la que ha servido a Rainer Kessler para proponer una historia social del antiguo Israel, una historia de ritmo lento atenta a los cambios de las formas sociales y de gran valor para la exégesis socio-histórica del Antiguo Testamento (Kessler, Historia social del antiguo Israel; Idem, “¿Escribir una historia social del antiguo Israel?”).

28 “Todos los niveles, todos los miles de niveles, todas las miles de fragmentaciones del tiempo de la historia, se comprenden a partir de esta profundidad, de esta semi-inmovilidad; todo gravita en torno a ella." (Braudel, "La larga duración", 74). 
Una de las formas más antiguas de registrar el lenguaje oral es la escritura. En ella, el lugar de los fonemas es ocupado por los grafemas haciendo posible la fijación del discurso y de su estructura basada en oraciones. En el lenguaje oral, el discurso hablado desaparece rápidamente, pero en el lenguaje escrito el discurso permanece gracias a los signos que lo dejan consignado en la piedra, el papiro, el papel o el cristal líquido, y así lo inscriben también en el tiempo.

El filósofo y teólogo Paul Ricoeur advierte que la temporalidad del discurso, en una conversación, es diferente a la que se da en la lectura de un texto que ha quedado escrito, para ser leído por diferentes personas y comunidades mucho tiempo después. En la conversación se intenta fijar un discurso fugaz en sí mismo; en la lengua se intenta fijar en virtud del discurso: “...solo se hace en razón de lo que debe ser fijado, el discurso." ${ }^{29}$ En la escritura, en cambio, la fijación se abre a la mediana y a la larga duración atendiendo al significado.

Una vez fijado en el tiempo por medio de la escritura, ese "acontecimiento del lenguaje" ${ }^{30}$ llamado discurso se ve liberado del fatídico poder del olvido, al convertirse en lugar de peregrinaje constante por parte de una impredecible variedad de lectores y lectoras provenientes de diferentes lugares y épocas. No obstante, debe notarse que si la expresión clásica verba volant, scripta manent es cierta, no lo es porque la escritura fije el acontecimiento del "decir", sino porque ella fija lo "dicho".

En la escritura se fija el significado del acontecimiento como habla, mas no como acontecimiento mismo. Es así como, al pasar del análisis del lenguaje al análisis del discurso, se transita del acontecimiento a la significación, siguiendo la realización del discurso en la escritura. Del mismo modo, las acciones se fijan en el tiempo como historia en virtud de su significado; de ahí la responsabilidad del hacer en la acción y la objetividad de lo hecho por medio de ella. La atención puesta en la fijación de lo dicho no debe conducir a desconocer la prioridad ética del decir.

Lo Dicho se constituye de contenidos, pero el Decir es una acción que lo trasciende y que no puede ser sistematizada, expresada o dicha. Lo Dicho puede ser comprendido y tematizado, pero el Decir no [...]. El Decir es el rostro, se escapa de la dinámica del ser e instaura el orden del discurso. ${ }^{31}$

\footnotetext{
${ }^{29}$ Ricoeur, "Le modèle du texte: l'action sensée considérée comme un texte", 207.

${ }^{30}$ Ibid., 206.

${ }^{31}$ López, De la autonomía a la pasividad, 99-100.
} 
En la concepción de la teología de la historia como teología de la acción esto reviste especial importancia, pues los límites para fijar los efectos del discurso en la escritura son inversamente proporcionales a los alcances propios del actuar en la historia. Si el decir escapa a lo dicho, fijo en la historia para la posteridad, las consecuencias históricas es lo único del actuar que permanece en el tiempo para ser interpretado. El filósofo y teólogo Emmanuel Lévinas es quien mejor ha captado lo irrecuperable que es el presente responsable de la acción humana:

Un movimiento lineal de regresión -una retrospectiva que se remonte hasta un pasado muy lejano, tan largo como la serie temporal- no podrá jamás llegar a lo pre-original absolutamente diacrónico, irrecuperable por medio de la memoria y de la historia. ${ }^{32}$

Advertida la prioridad ética de la acción, es posible retomar el análisis de la acción significativa desde el modelo del texto. Ricoeur acude a la teoría del acto de habla para distinguir -con John Langshaw Austin ${ }^{33}$ y John Rogers Searle ${ }^{34}$ - entre los planos locucional, ilocucional y perlucional. Se trata de atender a lo que se dice cuando se dice, lo que se hace en el decir y lo que se hace por medio del decir.

En la escritura, el recurso a los modos indicativo, imperativo y subjuntivo, entre otras herramientas gramaticales, sirve para reflejar algo de la fuerza ilocucionaria del acto de habla, pero con gran limitación. Esta dificultad de fijar el acto ilocucionario, tan evidente en el ámbito del habla mediante la prosodia, la mímica y la gesticulación, deja en evidencia que "la fuerza ilocucional está menos plenamente inscrita en la gramática de lo que está la significación proposicional”. ${ }^{35}$

Por su parte, la carga perlocucional es "lo menos discursivo del discurso" $36 \mathrm{y}$ escapa por completo a la inscripción en signos escritos, quedando apenas en la forma de "discurso como estímulo". ${ }^{37}$ No obstante, como la significación abarca "todos los aspectos y todos los niveles de la exteriorización intencional que hace posible la inscripción del discurso" 38 , comprender un discurso no solo implica comprender lo enunciado.

\footnotetext{
${ }^{32}$ Lévinas, Autrement qu'être ou au-delà del'essence, 24.

${ }^{33}$ Austin, Cómo hacer cosas con palabras.

${ }^{34}$ Searle, Actos de habla. Ensayo de filosofía del lenguaje.

${ }^{35}$ Ricoeur, "Le modèle du texte", 208.

${ }^{36}$ Ibid., 208.

${ }^{37}$ Ibid., 209.

${ }^{38}$ Ibid., 209.
} 
Además de captar lo dicho, la comprensión comporta también la captación de la fuerza ilocucional y la acción perlocucional. Esta dificultad evidente, en los planos ilocucional y perlocutivo, en los que el decir trasciende éticamente lo dicho, representa un notable desafío para una teología que quiera permanecer atenta a las Sagradas Escrituras, no como cuerpo muerto, y a las doctrinas, no como anquilosada tradición, sino como hacer y decir originales. ${ }^{39}$

Del mismo modo como el discurso se fija por medio de la escritura, la interacción humana se puede inscribir, como si se tratara de un texto objetivado. "La acción significativa, se puede convertir en objeto de la ciencia sin perder su carácter de significatividad gracias a un tipo de objetivación semejante a la fijación operada por la escritura" ${ }^{40}$, afirma Ricoeur.

Tal objetivación es posible gracias a los rasgos mismos de la acción, que la hacen objeto de interpretación teológica a partir de su aparición en el instante presente y de sus vestigios permanentes en el tiempo. Más allá de comprender la acción en su fugacidad, se trata de captar el obrar como enunciación, de interpretar el significado de la acción que se desprende del acontecimiento de la acción.

De la misma manera que la fijación por la escritura se hace posible por la dialéctica de una exteriorización intencional, inmanente al mismo acto de discurso, una dialéctica semejante [...] permite que la significación de la acción se desprenda del acontecimiento de la acción. ${ }^{41}$

Ricoeur coincide con Austin al afirmar que la acción posee una estructura análoga a la estructura del acto de habla, pues tiene un contenido proposicional identificable, una fuerza ilocucionaria y un efecto performativo.

Distinguimos así el acto locucionario (y dentro de él los actos fonéticos, "fácticos" y "réticos") que posee significado; el acto ilocucionario, que posee una cierta fuerza al decir algo; y el acto perlocucionario, que consiste en lograr ciertos efectos por (el hecho de) decir algo. ${ }^{42}$

\footnotetext{
39 "La teología está urgida de establecer los análisis perlocutivos que operan extratextualmente, fuera del texto y más allá del texto, cuando el discurso del texto se convierte en acción en obediencia al texto, al discurso del texto, al referente del texto (referenz), al mundo diferente y posible mostrado por el texto. El decir y los decires propios de las especializaciones funcionales bíblica y sistemática están solicitados con urgencia de reencontrar en ellos mismos la indisoluble conjunción del hacer original con el decir original, en modo que puedan de nuevo resolverse para el mundo del lector en acciones del decir y en garantía del hacer." (Parra, "De camino hacia la teología de la acción”, 154-155).

${ }^{40}$ Ricoeur, "Le modèle du texte", 213.

${ }^{41}$ Ibid., 214.

${ }^{42}$ Austin, Cómo hacer cosas con palabras, 167.
} 
En el acto de habla, el contenido proposicional de la acción permite una dialéctica entre acontecimiento y significación. Sin embargo, tal como advierte el filósofo inglés Anthony Kenny ${ }^{43}$, también la estructura proposicional de la acción puede verse claramente en los verbos de acción que admiten pluralidad de argumentos complementarios.

Por ejemplo, "el artista realizó su obra", "la fundió en bronce", "la completó antes de morir", "la exhibió en Medellín", "la reprodujo después de su violenta destrucción", son descripciones diferentes de la acción de un artista sobre la misma obra, y a ellas es posible seguir sumando enunciados.

Las diferentes posibilidades abiertas por los diversos tiempos verbales de la acción proporcionan también varias opciones para enunciarla en forma temporalmente diferenciada: "lo hice", "lo he hecho", "lo hago", "lo estoy haciendo", "he de hacerlo" y "lo haré" son aproximaciones diversas a una misma acción que indican realidades diferentes.

Esto ya introduce el asunto clave para la teología de la historia como teología de la acción a propósito de la prioridad ética del hacer como posibilidad y la prioridad objetiva de lo hecho como historia.

Las personas y las comunidades son el resultado de sus acciones y de las acciones de otros. Tal es una realidad histórica que merece toda la atención de la teología. Esto ya lo advertía Heidegger, a propósito de la temporalidad, en su conferencia ante la Sociedad Teológica de Marburgo, el 25 de julio de $1924^{44}$ :

El verdadero experto en cuestiones del tiempo es el teólogo [...] la teología se las ha tenido que haber con el tiempo bajo diversos aspectos. En primer lugar, la teología trata de la existencia humana en cuanto ser ante Dios y de su temporalidad en su relación con la eternidad. Dios mismo no necesita ninguna teología; su existencia no está fundamentada en la fe. En segundo lugar, la fe cristiana debe tener en sí misma una relación con algo que aconteció en el tiempo; en un tiempo que, según el mensaje que hemos oído, fue el "de la plenitud de los tiempos..." ${ }^{\prime 5}$

La realidad pascual que dio origen a la Iglesia se desprende de la resurrección del Señor, en virtud de su significado para los creyentes, y trasciende en la historia a partir

\footnotetext{
${ }^{43}$ Kenny, Action, Emotion and Will.

${ }^{44}$ Heidegger, "El concepto del tiempo en la ciencia histórica".

${ }^{45}$ Ibid., 24.
} 
de sus efectos, más que como acontecimiento histórico mismo. La evidencia histórica de la resurrección es la Iglesia misma y debe orientar su acción como comunidad creyente. Esto ilustra cómo la prioridad ética de la acción deviene en prioridad objetiva de sus efectos.

Además del contenido proposicional, la "fuerza" y el "efecto" hacen parte también de la acción humana. Esto tiene importantes implicaciones para la enunciación teológica de la verdad revelada y de la interpretación de esta revelación consignada en las Sagradas Escrituras. Es lo que propone el teólogo colombiano Gustavo Baena con las siguientes palabras:

Si la palabra de Dios revelante de la orientación divina o trascendente, se manifiesta por medio del fenómeno [...], lo directamente aprehendido en el fenómeno, en cuanto palabra de Dios revelante, lo constituyen, ante todo, las determinaciones categoriales, que el hombre establece en su decisión libre para asumir responsablemente su existencia trascendental [...] las determinaciones categoriales son la objetivación histórica de la revelación trascendental. ${ }^{46}$

La determinación categorial de la acción humana es la objetivación de la voluntad divina que acontece en la historia. Trascendencia e inmanencia son las dos caras de una misma realidad. En este sentido, es posible concebir la trascendencia de la acción en su propia inmanencia.

La teología de la acción es posible porque el obrar tiene una estructura noemática que puede separarse de la interacción y convertirse en objeto de interpretación. En tal estructura noemática, además del contenido proposicional, el significado (noema) tiene rasgos ilocucionarios ${ }^{47}$ que permiten establecer modelos como el de la promesa ${ }^{48}$, arquetipo central para la fe judía y cristiana. La promesa hecha por Dios a su pueblo y el cumplimiento de tal promesa son las claves de interpretación de la historia para los judíos y para los cristianos.

\footnotetext{
${ }^{46}$ Baena, Fenomenología de la revelación. Teología de la Biblia y hermenéutica, 22-223

${ }^{47}$ Austin pone en evidencia tales rasgos ilocucionarios mediante una clasificación de verbos según la intensidad de su fuerza ilocucionaria en la primera persona singular del presente indicativo: verbos judicativos (considero que..., interpreto como..., entiendo que..., tomo $x$ como $y$ ), verbos ejercitativos (destituyo a..., intercedo por..., perdono a..., voto por...), verbos compromisorios (doy mi palabra, me comprometo a..., expreso mi intención de.., tomo partido por...), verbos comportativos (ofrezco disculpas por..., me solidarizo con..., agradezco que..., doy la bienvenida a...) y verbos expositivos (describo, pregunto, refiero, estoy de acuerdo con...) (Austin. Cómo hacer cosas con palabras, 198-210). 48 "Para comprender lo que es una promesa, debemos comprender qué es la condición esencial en virtud de la cual una acción dada debe ser considerada como una promesa. Esta condición esencial de Searle no está alejada de lo que Husserl llamaba sinngehalt, que abarca tanto el asunto (contenido proposicional) como la cualidad (fuerza ilocucionaria)." (Riceour, "Le modèle du texte", 215-216).
} 
Como el acto de habla, la acción en cuanto acontecimiento establece también una dialéctica entre su estatuto temporal y su estatuto lógico. El contenido proposicional de la acción y su fuerza ilocucionaria constituyen el contenido de sentido que hace posible la inscripción del significado; pero la dimensión histórica de la acción también tiene mucho que decir sobre el estatuto temporal de la acción; de ahí la importancia de la teología de la historia para la teología de la acción.

Máximas clásicas como quod factum, factum est evidencian la apertura del obrar a sus consecuencias, así como la relación entre la duración corta del hacer y la larga duración de lo hecho, una relación que la teología de la acción debe pensar a partir de la prioridad ética del actuar y de la prioridad objetiva de sus resultados en la historia.

En la acción orientada significativamente, el acto perlocutivo será evidente como huella, y se abrirá a la larga y a la mediana duración, para condicionar la vida futura más allá de lo previsto por el agente de la acción. Una generación está a merced de las consecuencias históricas de las acciones de las generaciones que la precedieron, tal como el texto está a merced de los lectores que en adelante habrán de ocuparse de él, interpretándolo, desde diferentes perspectivas.

\section{Significado y alteridad}

Antes de seguir adelante con la exploración del modo como se fija la acción en el tiempo, tal como el discurso lo hace mediante su inscripción, vale la pena retomar la idea de la escritura como fijación del discurso para preguntarse si en realidad ella sirve a la memoria o si traiciona la espiritualidad original y el sentido primero del discurso.

¿Acaso tenía razón el rey egipcio Tamus, en la narración platónica recordada por Ricoeur $^{49}$, al discutir con el dios Teut acerca de la escritura cuando este le daba a conocer las artes que había inventado? Teut explicaba la utilidad de cada arte y Tamus aprobaba o reprobaba, ponderando las ventajas y las desventajas de cada una. Cuando llegaron a la escritura dijo Teut: "Este conocimiento, oh rey, hará a los egipcios más sabios y más memoriosos. Tanto la memoria como la sabiduría han encontrado remedio." ${ }^{50}$

Sin embargo, lo que para el dios era una ventaja fue visto por el rey como una desventaja: "Esto producirá olvido en las almas de quienes lo aprendan, pues, por confiar en la escritura, dejarán de ejercitar su memoria y recordarán de forma externa, por marcas extrańas, y no desde su interior y por sí mismos." 51

\footnotetext{
${ }^{49}$ Ibid., 207.

${ }^{50}$ Platón, Fedro, 207.

${ }^{51}$ Ibid.
} 
Como sucede con los monumentos y otras producciones culturales que perduran, los documentos escritos sobreviven a sus autores y quedan a merced de la interpretación que se haga de ellos mediante procedimientos exegéticos. ${ }^{52}$ Esta exposición derivada de la objetivación suscita algunas cuestiones: ¿Es el significado auténtico de un texto el mismo que su autor le dio de una vez para siempre? ¿Puede decir lo mismo un texto cada vez que es leído en diferentes épocas y contextos? La respuesta debe ser negativa, pues de otro modo el texto estaría eternamente confinado al silencio y sus lecturas ulteriores estarían encerradas en un eterno retorno de lo mismo..$^{53}$

Sin novedad alguna en las lecturas de un mismo texto, ni siquiera sería posible el desarrollo de disciplinas como los estudios bíblicos. Sin embargo, hay en esta disciplina teológica una dicotomía en la que numerosos expertos han quedado atrapados por el prurito de un sentido inmanente desde el cual el texto permanece para siempre en silencio, una vez ha sido escrito ${ }^{54}$; mientras muchos otros lo están por el ideal romántico de dar con el sentido que el autor quiso dar al texto y de identificarlo con el sentido del texto mismo. ${ }^{55}$ En ambas perspectivas se pierde de vista que "el Evangelio vive en sus interpretaciones y las trasciende". ${ }^{56}$

\footnotetext{
${ }^{52}$ De acuerdo con Paul Ricoeur, mientras la comprensión (verstehen) se basa en el reconocimiento de lo que alguien quiere decir por medio de cualquier tipo de signos, la interpretación (auslegung) se limita a aquellos signos que han sido fijados en el tiempo, como los monumentos o los documentos escritos.

53 "La apropiación del significado del texto es, como hemos visto, una parte elemental del proceso de comprensión, por la sencilla razón de que los textos -especialmente los sagrados- piden actualización y quieren ser llevados y aplicados más allá de su situación de origen. Los textos quieren mantener su efecto y desplegar su significado para la mayor cantidad posible de lectores." (De Wit, Por un solo gesto de amor. Lectura de la Biblia desde una práctica intercultural, 117). "Lo que se lee, el resultado del acto de lectura, lo que se 'descubre' en el texto nunca es tan solo producto de un salto atrás, un salto hacia la vida de y el contexto del autor histórico, sino está siempre y profundamente determinado por lo que el lector o la lectora es, por el lugar en que vive, por su biografía, por sus experiencias." (De Wit y López, Lectura intercultural de la Biblia en contextos de impunidad en América Latina, 103).

54 "Para los analistas partidarios de una explicación sin comprensión, el texto sería una máquina de funcionamiento puramente interno al cual no habría que plantearle ninguna pregunta -considerada psicologizante-, ni aguas arriba al lado de la intención del autor, ni aguas abajo al lado de la recepción por parte de un auditorio, ni aun por el espesor del texto al lado de un sentido, o de un mensaje distinto de la forma misma, es decir, distinto del entrecruzamiento de los códigos realizado por el texto." (Ricoeur, "Expliquer et comprendre", 183).

55 "Para los hermeneutas románticos, en cambio, el análisis estructural surgiría de una objetivación ajena al mensaje del texto, él mismo inseparable de la intención de su autor: comprender sería establecer entre el alma del lector y la del autor una comunicación, incluso una comunión, semejante a la que se establece en un diálogo cara a cara." (Ibid.).
}

${ }^{56}$ López, La evangelización como práctica interpretativa, 50. 
Esto vale decirlo también sobre la acción significativa interpretada como un texto, pues muchas acciones quizás permanecen en la memoria de personas y comunidades apenas recordadas como acontecimientos en la historia, sin que se reconozca su significación histórica. Quizás los misterios fundantes de la fe, como la muerte y resurrección de Jesús, sean tenidos por muchos creyentes como acontecimientos propios de un tiempo pasado y subjetivo, carentes de toda significación histórica en la larga y la mediana duración.

Ese es el riesgo que corre una teología de la acción que solo preste atención al actuar fugaz del tiempo subjetivo, sin tener en cuenta la prioridad objetiva de lo hecho, como perspectiva histórica de mediana o larga duración, que permite comprender mejor el sentido de la acción humana presente. Visto desde una perspectiva histórica, el sentido de una acción no es totalmente dado por el agente, pues la acción queda expuesta en el tiempo como objeto de interpretación.

Ricoeur muestra cómo, en una conversación, el carácter auto-referencial del discurso es evidente por la coincidencia de la intención subjetiva de quien habla y el significado de lo que quiere decir. En el ámbito del habla no hay mayor diferencia entre las preguntas "¿qué quiere usted decir?” y “¿qué significa lo que usted dice?” 57

El pensador francés señala también cómo en el discurso escrito hay una diferencia vital entre la intención del autor y el significado del texto que ha creado: la intención del autor y la intención del texto no son la misma. El texto le sobrevive al autor, rompe con la psicología de este y se sustrae al horizonte en que fue creado.

Lo que dice el texto importa más que aquello que el autor ha querido decir, de ahí que en adelante toda exégesis despliegue sus procedimientos en la circunscripción de una significación que ha roto sus vínculos con la psicología de su autor. ${ }^{58}$

La exteriorización del discurso mediante signos lo enajena y, al posibilitar su autonomía semántica de esta manera, deja expuesta también la "espiritualidad efectiva del discurso" ${ }^{59}$ Es así como Ricoeur desarrolla el postulado gadameriano de la alteridad del texto hasta sus últimas consecuencias:

El que intenta comprender un texto está dispuesto a dejar que el texto le diga algo. Por eso una conciencia formada hermenéuticamente debe estar dispuesta

\footnotetext{
${ }^{57}$ Ricoeur, "Le modèle du texte”, 210.

${ }^{58}$ Ibid., 210.

${ }^{59}$ Ibid., 210.
} 
a acoger la alteridad del texto. Pero tal receptividad no supone la "neutralidad" ni la autocensura, sino que implica la apropiación selectiva de las propias opiniones y prejuicios. Es preciso percatarse de las propias prevenciones para que el texto mismo aparezca en su alteridad y haga valer su verdad real contra la propia opinión. ${ }^{60}$

Más allá, en la perspectiva de Ricoeur, el texto es otro, no solo respecto de su lector sino también de su autor. Esto es expresado por Umberto Eco, un lustro después de la publicación de su novela El nombre de la rosa, con las siguientes palabras: "Allí está el texto, que produce sus propios efectos de sentido. Independientemente de mi voluntad [...]. El autor debería morirse después de haber escrito su obra. Para allanarle el camino al texto." ${ }^{61}$

La escisión de la acción humana respecto de su agente es también un elemento constitutivo del obrar, mediante el cual la acción humana se hace autónoma para abrir el espacio a su dimensión social. Allí se abre una brecha entre la corta y la larga duración, entre el tiempo subjetivo y el tiempo social, un abismo que solo puede ser salvado por la teología de la acción mediante una teología de la historia que permanezca más atenta al sentido histórico de la acción que al acontecimiento mismo del obrar.

La acción con sentido se desprende de su agente, como lo hace el texto de su autor, para quedar registrada en la historia en virtud de sus propias consecuencias. Nuestros propios actos se nos escapan en los efectos no previstos. Esta es una realidad antropológica innegable, que ha sido descrita bellamente por Lévinas con las siguientes palabras:

Al extender la mano para acercar una silla, he arrugado la manga de mi chaqueta, he rayado el suelo, he dejado caer la ceniza de mi cigarrillo. Al hacer lo que quería hacer, he hecho miles de cosas que yo no había deseado. El acto no ha sido puro, he dejado las huellas [...]. En cuanto la torpeza del acto se vuelve contra el fin perseguido, estamos en la plena tragedia. ${ }^{62}$

El curso de los acontecimientos impide a la acción desvanecerse, como la escritura salva al discurso de su fugacidad. El acontecimiento se fija en el tiempo social como efecto duradero, como marca persistente, pero lo hace a partir de su significado. Piénsese, por ejemplo, en el desenlace de la última visita de Jesús a Jerusalén, en el asesinato del archiduque Francisco Fernando en Sarajevo, o el de Jorge Eliécer Gaitán

\footnotetext{
${ }^{60}$ Gadamer, "Sobre el círculo de la comprensión”, 66.

${ }^{61}$ Eco, "Apostillas a El nombre de la Rosa", 740.

${ }^{62}$ Levinas "L'ontologie est-elle fondamentale?", 14.
} 
en el centro de Bogotá. Ninguno de los perpetradores de estas muertes violentas pudo haber previsto las consecuencias de su actuar; sin embargo, el significado de tales acontecimientos marcó la historia de las generaciones futuras en la larga duración.

El tiempo social es el lugar de los efectos duraderos de la acción.

El tiempo social no es solamente aquella cosa que ha sucedido; es también el lugar de efectos perdurables, de configuraciones persistentes. Una acción deja una "huella", fija su "marca", cuando contribuye a la emergencia de tales configuraciones, que devienen en los documentos de la acción humana. ${ }^{63}$

En esto consiste la dimensión social de la acción: en las consecuencias no previstas por el actor que la convierten en fenómeno histórico y semántico.

En acciones simples, como levantar la mano o sonreír, el significado (noema) coincide con la intención (noesis), pero hay acciones más complejas que no permiten establecer fácilmente vínculos entre las consecuencias y los agentes de las acciones que las produjeron; de ahí la importancia de la relación entre teología de la acción y teología de la historia.

Inspirado en el filósofo moral Joël Feinberg y su causal "efecto acordeón" ${ }^{4}$, Ricoeur ve la historia como el lugar en que la acción humana deja sus marcas:

¿No podría uno decir que la historia constituye en sí misma el archivo de la acción humana? La historia es esa cuasi-"cosa" sobre la cual la acción humana deja una "huella", fija su "marca". De ahí la posibilidad de los "archivos". Con anterioridad a los archivos intencionalmente escritos por los memorialistas, hay un proceso continuo de "registro" de la acción humana, que es la historia misma en tanto que suma de "marcas", cuyo destino escapa al control de los actores individuales. ${ }^{65}$

Como en una obra de teatro en la que los actores desconocen la trama, cada acto en su dimensión social es registrado en la historia. "La acción humana se convierte en acción social cuando se inscribe en los archivos de la historia." ${ }^{66}$ Esto debe llevar a la teología de la acción a subrayar la prioridad ética de la acción humana y la prioridad objetiva de sus resultados históricos en la mediana y la larga duración.

\footnotetext{
${ }^{63}$ Ricoeur, "Le modèle du texte", 217.

${ }^{64}$ Según este efecto, si Pedro hace que la puerta se abra y la puerta golpea a Pablo, Pedro no solo abrió la puerta sino fue quien golpeó a Pablo (Feinberg, Doing and Deserving).

${ }^{65}$ Ricoeur, "Le modèle du texte", 218.

${ }^{66}$ Ibid.
} 
Liberado del fardo psicológico del agente y de su ambiente originario, el obrar humano deviene en instituciones cuya significación no coincide con las intenciones de los agentes. Esto fue lo que sucedió con la iglesia primitiva que, en el marco de la experiencia pascual, surgió de la predicación y de la praxis de Jesús, sin que el Señor hubiese concebido tal división al interior del judaísmo que quería reformar proféticamente. ${ }^{67}$

Esta institución, cuya práctica ha marcado en la posteridad la vida de los creyentes, está llamada a prolongar la acción de Jesús en la historia. "El espíritu del Resucitado, como existencial divino, se revela precisamente por los efectos reales de transformación de la vida de los miembros de la comunidad.” ${ }^{8}$

\section{Intencionalidad y trascendencia}

La intencionalidad del discurso ${ }^{69}$ es algo que se evidencia en cada conversación y en todo texto. Como decir es siempre decir algo, así mismo, hacer es hacer siempre algo. En eso consiste la intencionalidad de la acción.

Al hablar, los interlocutores hacen referencia a un mundo común, muchas veces en forma ostensible. De la misma manera, en cualquier texto, el discurso refiere un mundo y ese mundo es el mundo del lector. En la conversación, el discurso es dirigido a alguien en forma evidente y directa, pero esta realidad es sobrepasada por el texto escrito en cuanto dirigido a cualquier persona que sepa leer y por la acción significativa en cuanto historia abierta a la interpretación ulterior.

Debido a la orientación universal y más allá del diálogo directo, en el texto escrito la intencionalidad del discurso se abre en forma trascendente.

Gracias a la escritura, el discurso adquiere una triple autonomía semántica: en relación con la intención del hablante, con la recepción del auditorio primitivo, y con las circunstancias económicas, sociales, culturales de su producción. ${ }^{70}$

\footnotetext{
${ }^{67}$ Aguirre, "Reino de Dios y compromiso ético".

${ }^{68}$ Baena, Fenomenología de la revelación, 243.

${ }_{69}$ "El gran descubrimiento de la fenomenología, bajo la condición misma de la reducción fenomenológica, sigue siendo la intencionalidad, es decir, en su sentido menos técnico, el primado de la conciencia de alguna cosa sobre la conciencia de sí. Pero esta definición de la intencionalidad es todavía trivial. En su sentido riguroso, la intencionalidad significa que el acto de procurar algo no se alcanza sino a través de la unidad identificable y re-identificable del sentido buscado, lo que Husserl llama el "noema", o correlato intencional del propósito "noética". (Ricoeur, "De l'interprétation”, 30).
}

${ }^{70}$ Ibid., 35. 
Liberado de la psicología de su autor y de las referencias ostensibles de su ambiente genético, el texto despliega su mundo, que es el mundo inédito de la vida humana. "Este es el mundo del texto que interviene en el mundo de la acción para configurarlo de nuevo o, si se puede atrever a decir, para transfigurarlo." ${ }^{\prime 1} \mathrm{La}$ alteridad semántica deviene en apertura trascendente a otros mundos, como modos posibles de ser. Es así como el texto revela la espiritualidad de la escritura: el texto se dirige al público que él mismo crea. Al mismo tiempo, la subjetividad del lector es.

...el fruto de la lectura y el don del texto, y portadora de las expectativas con las que ese lector aborda y recibe el texto [...]. Comprenderse es comprenderse ante el texto y recibir de él las condiciones de un otro ser distinto del yo que procede de la lectura. $^{72}$

Del mismo modo, comprender la propia acción es comprenderla en el marco de la historia. El tiempo subjetivo se capta mejor bajo la luz de la mediana y la larga duración. Nuestra comprensión de la acción es más clara a la luz de la comprensión de nuestra historia, hecha por otros, y el valor ético de la propia acción es más evidente como historia, hecha para otros.

El texto revela su mundo al lector como conjunto de "referencias abiertas por el texto; sería aún mejor decir que estas referencias abren el mundo"73; de ahí que entender un texto sea, para Ricoeur, "al mismo tiempo esclarecer nuestra propia situación [...] interpolar entre los predicados de nuestra situación todas las significaciones que convierten nuestro Umwelt en un Welt". ${ }^{74}$ Nuestro ámbito de la acción en el tiempo subjetivo deviene en un mundo para los otros en el tiempo social.

Ricoeur advierte cómo la escritura proporciona nuevas dimensiones del propio ser-en-el-mundo, "al liberarse no solo de su autor, sino también de la estrechez de la situación dialogal, revela el destino del discurso, que es el de proyectar un mundo". 75 Así mismo, la importancia de una acción significativa trasciende la pertinencia de su situación inicial y desarrolla significados que pueden ser actualizados en circunstancias diferentes a las de su ambiente genético.

${ }^{71}$ Ibid., 27.

72 Ibid., 33.

${ }^{73}$ Idem, "Le modèle du texte", 211.

${ }^{74}$ Ibid., 211.

${ }^{75}$ Ibid., 212. Así lo había propuesto antes Martin Heidegger a propósito del comprender como posibilidad de ser: "Lo que se puede en el comprender en cuanto existenciario no es ningún 'algo', sino el ser en cuanto existir. En el comprender reside existenciariamente la forma de ser del 'ser ahî' como 'poder ser' [...] es primariamente 'ser posible'.' (Heidegger, El ser y el tiempo, 161). 
Esa apertura trascendental da a la acción una pertinencia perenne. "La significación de un acontecimiento importante excede, sobrepasa, trasciende las condiciones sociales de su producción y puede ser re-hecha en nuevos contextos sociales." $76 \mathrm{Tal}$ como los textos desarrollan nuevas referencias y constituyen nuevos mundos, algunos productos derivados de la acción orientada significativamente sobrepasan las condiciones sociales de su producción. ${ }^{77}$ En ellos, la acción adquiere actualidad en nuevos procesos históricos trascendiéndose a sí misma. Es así como las acciones de Jesús narradas en el Nuevo Testamento están consignadas allí para ser actualizadas mediante el obrar de los creyentes a lo largo de la historia, y abren nuevos cursos de acción orientados hacia la concreción histórica del Reino de Dios.

La espiritualidad del discurso, que abre nuevos mundos posibles, aparece en la acción como trascendencia que se sobrepone a su contexto genético, le permite realizar nuevos mundos posibles y la dota de una significación inagotable más allá del tiempo subjetivo. "La realización actual del hombre radica en la concretización histórica y efectiva de su propia trascendencia." 78

Más allá del acontecimiento, como si se tratara de un texto, el significado de la acción humana se dirige a generaciones futuras de intérpretes. El significado de la propia acción se halla abierto ante el juicio de la historia, pero interpretarla en el marco de la mediana y la larga duración ayuda a comprender mejor su significado en el presente.

Por abrir nuevas referencias, la acción recibe nueva pertinencia, "los actos humanos están también a la espera de que interpretaciones nuevas decidan sobre su significación". ${ }^{79}$

Todos los acontecimientos y todos los actos significativos están, de esta manera, abiertos a este tipo de interpretación práctica por la praxis presente [...] si la significación de un acontecimiento es el sentido que le es dado por las interpretaciones ulteriores, la interpretación de los contemporáneos no tiene ningún privilegio particular en este proceso. ${ }^{80}$

La teología de la acción debe prestar especial atención a esta imprevisibilidad en que se manifiesta la prioridad objetiva de lo hecho sobre la acción responsable del

\footnotetext{
${ }^{76}$ Ricoeur, "Le modèle du texte", 219.

77 “Una obra no refleja solamente su tiempo, sino que ella abre un mundo que lleva en sí misma." (Ibid., 220).

${ }^{78}$ Baena, Fenomenología de la revelación, 221.

${ }^{79}$ Ricoeur, "Le modèle du texte", 220.

${ }^{80}$ Ibid., 220.
} 
presente y, lejos de negarla, la compromete con la historia. La teología de la acción no se agota en la percepción de la acción y en su analítica ${ }^{81}$; al contrario, permite proyectar la acción en forma responsable, al atender las dimensiones históricas del actuar en los planos de la mediana y la larga duración.

Para la teología, la acción libre y liberadora de Dios en la historia se da gracias a la trascendencia de la acción humana en la historia. Como afirma Baena, hacemos historia porque nuestra acción trasciende en un sentido auténtico de liberación o en un sentido inauténtico alienante:

Aunque la existencia del hombre como posición del ser absoluto sea necesaria, sin embargo el modo como el hombre la ejecuta en su conocer y obrar, depende de la libre posición que el hombre mismo, a su vez, establezca al decidir autónomamente sus operaciones intencionales, ya sea en forma auténtica o inauténtica. $^{82}$

Las comunidades creyentes, que ven en la historia el actuar salvífico de Dios, pueden interpretar el sentido de la acción humana como sentido salvífico en la historia, pero esto implica reconocer los mundos posibles que las Sagradas Escrituras ponen delante de ellas. Tales mundos posibles han de ser puestos por obra aquí y ahora en forma auténtica, pues las opciones hechas efectivamente en el presente fugaz perdurarán en la historia como huella que condicionará la vida futura en la Tierra.

En la convergencia histórica de la acción divina y de la acción humana, aun como pasividad ante el sufrimiento y el mal, las acciones individuales, colectivas y comunitarias de los creyentes ${ }^{83}-\mathrm{y}$ también las de quienes no creen o viven otra $\mathrm{fe}^{84}-\mathrm{se}$ abren en la mediana y la larga duración a la realización histórica del Reino de Dios.

Este proceder de Dios creando seres humanos trascendiéndose en ellos [...] esto es, saliendo de sí mismos en función de sus hermanos, es lo que cons-

81 "Las dos etapas anteriores, según la fuerza perlocutiva de los análisis, dan espacio a la etapa de planificación en la cual la acción sentida y observada, en la etapa perceptiva y reconfigurada teóricamente en la etapa analítica, encuentra nuevos motivos, impulsos y modos para ser resignificada, reconducida y reorientada hacia las supremas finalidades de validez de los discursos en la facticidad de la historia y a su incidencia transformadora en el mundo real de la vida personal y social, política y eclesial." (Parra, "De camino a la teología de la acción", 164).

${ }^{82}$ Baena, Fenomenología de la revelación, 218.

83 "El hombre como ser material y por esa misma razón, como principio de espacio y tiempo, no es un ente único aislado, sino uno entre muchos, cuya esencia individual solo es plenamente realizable en un ámbito comunitario espacio temporal, es decir, una comunidad.” (Ibid., 221).

${ }^{84}$ López, "Moral cristiana y moral humana”. 
tituye el ámbito histórico comunitario espacio temporal, o sea el lugar de la responsabilidad individual y comunitaria. ${ }^{85}$

\section{Observaciones finales}

En este artículo se ha querido profundizar en la importancia que tiene, para la teología de la acción, la aplicación del método de interpretación textual a la acción humana, según el pensamiento de Paul Ricoeur, debido a las relaciones que este autor establece entre el texto, la acción y la historia. ${ }^{86}$

Aunque tal recurso no constituye una novedad en sí mismo ${ }^{87}$, se ha hecho aquí un aporte nuevo al prestar especial atención a la dimensión histórica de la acción, introduciendo el problema de la duración histórica, así como la relación entre el tiempo subjetivo y el tiempo social.

De la manera como una persona es el resultado de sus actos, también lo es de las consecuencias históricas que han tenido los actos de otros sobre ella. La acción es huella que permanece en el tiempo como vestigio histórico. Lo hecho exterioriza el hacer, y esta objetivación hace comprensible la acción para sus futuros intérpretes y agentes de transformación.

El aporte hecho a la teología de la acción y a la teología de la historia está en haber advertido sobre la relación entre el presente de la acción humana y la dimensión histórica de sus efectos abiertos a la interpretación futura, pues -como dice Braudel"presente y pasado se aclaran mutuamente, con luz recíproca". ${ }^{88}$

Comprender la acción humana implica conjeturar sobre su sentido presente, su relación con los procesos de larga y mediana duración, así como sus ulteriores significados emergentes como mundos posibles. Sin embargo, a partir de la concepción de mundo como posibilidad, debe advertirse que el ámbito de la interpretación no agota la finalidad transformadora de la teología de la historia propuesto aquí.

Tal finalidad se refleja en el esfuerzo profético de historizar la utopía del Reino de Dios. Esto es lo que expresa Ellacuría con las siguientes palabras:

La profecía es pasado, presente y futuro, aunque es sobre todo presente de cara al futuro, es futuro de cara al presente. La utopía es historia y metahistoria, aun-

\footnotetext{
${ }^{85}$ Baena, Fenomenología de la revelación, 225.

86 "Nada es más interesante que el juego de remisiones entre texto, acción e historia." (Ricoeur, "Expliquer et comprendre", 182).

${ }^{87}$ Lara, "Fides et praxis".

${ }^{88}$ Braudel, "La larga duración”, 80.
} 
que es sobre todo metahistoria, nacida, sin embargo de la historia y remitente inexorablemente a ella. ${ }^{89}$

Las dimensiones históricas de la acción pueden ser mejor apreciadas por la teología, si se atiende a la dialéctica entre el tiempo subjetivo y el tiempo social. Del mismo modo, la acción presente puede ser dirigida atendiendo a su interacción con procesos de mediana y de larga duración. Agustín de Hipona, el primer autor de una teología de la historia ${ }^{90}$, había propuesto ya la temporalidad como relación entre diferentes tiempos presentes:

Hablamos de "tiempo largo" y "tiempo breve" y no lo decimos sino del pasado o del futuro [...]. Más propiamente debiera decirse que los tiempos son tres: presente de lo pasado, presente de lo presente y presente de lo futuro [...]. El presente de lo pasado es la memoria, el presente de lo presente la atención, el presente de lo futuro, la expectación. ${ }^{91}$

La perspectiva teológica de la acción presentada aquí permite concebir el estatuto epistemológico de la teología de la historia a partir de la fijación del significado de la acción transformadora, su disociación de la intención del agente mediante sus efectos y las referencias de mundo a la universalidad de destinatarios que buscarán y posibilitarán en la historia la presencia actuante de Dios.

Por su parte, la teología de la acción puede trascender el plano de la corta duración, para comprender el obrar humano en su relación con el actuar divino, a partir de la objetividad de sus consecuencias abiertas a interpretaciones inéditas, evidentes en las perspectivas de la larga y la mediana duración.

\section{Bibliografía}

Aguirre, Rafael. "Reino de Dios y compromiso ético." En Conceptos de ética teológica, dirigido por Marciano Vidal, 69-87. Madrid: Trotta, 1992.

Agustín de Hipona. ¿Qué es el tiempo? Libro XI de Las Confesiones. Madrid: Trotta, 2011.

Austin, John. Cómo hacer cosas con palabras. Barcelona: Paidós, 1991.

Baena, Gustavo. Fenomenología de la revelación. Teología de la Biblia y hermenéutica. Estella (Navarra): Verbo Divino, 2011.

\footnotetext{
${ }^{89}$ Ellacuría, “Utopía y profetismo”, 394.

${ }^{90}$ Ferrater, Cuatro visiones de la historia universal, 18.

${ }^{91}$ Agustín de Hipona, ¿Qué es el tiempo? Libro XI de Las Confesiones, 59. 67-69.
} 
Bossuet, Jacques Bénigne. Discurso sobre la historia universal. Barcelona: Editorial Cervantes, 1940.

Braudel, Fernand. El Mediterráneo y el mundo mediterráneo en la época de Felipe II. México: Fondo de Cultura Económica, 2001.

. "La larga duración." En La historia y las ciencias sociales, por F. Braudel, 60106. Madrid: Alianza, 1970.

Concilio Vaticano II. "Constitución pastoral Gaudium et spes sobre la Iglesia en el mundo actual." En Concilio Vaticano II. Documentos completos, 135-220. Bogotá: San Pablo, 1993.

De Wit, Hans. Por un solo gesto de amor. Lectura de la Biblia desde una práctica intercultural. Buenos Aires: Isedet, 2010.

De Wit, Hans y Edgar López (dirs.) Lectura intercultural de la Biblia en contextos de impunidad en América Latina. Bogotá: Facultad de Teología. Pontificia Universidad Javeriana, 2013.

Eco, Umberto. "Apostillas a El nombre de la Rosa." En El nombre de la rosa, por U. Eco, 735-776. México: Random House Mondadori, 2004.

Ellauría, Ignacio. Filosofía de la realidad histórica. San Salvador: UCA Editores, 1990. . "Historicidad de la salvación cristiana." En Mysterium liberationis dirigido por Ignacio Ellacuría y Jon Sobrino, I, 323-372. San Salvador: UCA Editores, 1993. . “Utopía y profetismo." En Mysterium liberationis, dirigido por Ignacio Ellacuría Ignacio y Jon Sobrino, I, 393-442. San Salvador: UCA Editores, 1993.

Feinberg, Joël. Doing and Deserving. Princeton: Princeton University Press, 1970.

Ferrater, José. Cuatro visiones de la historia universal. Madrid: Alianza, 1988.

Gadamer, Hans-Georg. "Sobre el círculo de la comprensión". En Verdad y método II, por H.-G. Gadamer, 63-70. Salamanca: Sígueme, 2002.

Hegel, Wilhelm Friedrich. Lecciones sobre la filosofía de la historia universal. Madrid: Alianza, 2004.

Heidegger, Martin. El concepto de tiempo. Madrid: Trotta, 2011.

- "El concepto del tiempo en la ciencia histórica". En Tiempo e historia, por M. Heidegger, 13-38. Madrid: Trotta, 2009.

. El ser y el tiempo. México: Fondo de Cultura Económica, 2009. 
Kant, Emmanuel. "Idea de una historia universal en sentido cosmopolita". En Filosofia de la historia, 39-65. México: Fondo de Cultura Económica, 1998.

Kenny, Anthony. Action, Emotion and Will. London: Routledge, 1963.

Kessler, Rainer. “¿Escribir una historia social del antiguo Israel?” Theologica Xaveriana 151 (2004): 503-518. . Historia social del Antiguo Israel. Salamanca: Sígueme, 2013.

Lara, David. "Fides et praxis. Una teología de la acción humana". En Theologica Xaveriana 169 (2010): 81-104.

Levinas, Emmanuel. Autrement qu'être ou au-delà del'essence. Leiden: Martinus Nijhoff, 1978.

. "L'ontologie est elle fondamentale?" En Entre nous. Essais sur le penser-à-l'autre, por E. Lévinas, 12-22. Paris: Éditions Grasset \& Fasquelle, 2007.

Lonergan, Bernard. Method in Theology. New York: Herder \& Herder, 1972.

López, Edgar. De la autonomía a la pasividad. Bogotá: Pontificia Universidad Javeriana, Facultad de Teología, 2004.

- "En el perdón de las víctimas está nuestra esperanza". Mirada teológica 2 (2015): 16-21.

. La evangelización como práctica interpretativa. Bogotá: Facultad de Teología. Pontificia Universidad Javeriana, 2009.

. "Moral cristiana y moral humana." Theologica Xaveriana 139 (2001): 381-394.

Parra, Alberto. "De camino hacia la teología de la acción". Theologica Xaveriana 175 (2013): 143-171.

. Textos, contextos y pretextos. Teología fundamental. Bogotá: Pontificia Universidad Javeriana, Facultad de Teología, 2003.

Platón. Fedro. Madrid: Akal, 2010.

Ricoeur, Paul. "De l'interprétation." En Du texte à l'action. Essais d'hermeneutique II, por P. Ricoeur, 13-39. Paris: Éditions de Seuil, 1986.

. "Expliquer et comprendre." En Du texte à l'action. Essais d'hermeneutique II, por P. Ricoeur, 179-203. Paris: Éditions de Seuil, 1986.

. "Le modèle du texte: l'action sensée considérée comme un texte." En Du texte à l'action. Essais d'hermeneutique II, por P. Ricoeur, 205-236. Paris: Éditions de Seuil, 1986. 
Schillebeeckx, Edward. Los hombres relato de Dios. Salamanca: Sígueme, 1995.

Searle, John. Actos de habla. Ensayo de filosofía del lenguaje. Madrid: Cátedra, 1994.

Tornos, Andrés. “Sobre teología de la historia” Isegoría 4 (1991): 174-182. 